\title{
Organizational Citizenship Behavior and Organizational Commitment among Clinical Nurses in Bangladesh
}

\author{
Md. Mahmud Hossain \\ Dhaka Medical College Hospital, Dhaka, Bangladesh \\ Email: tamalmahmudpgh@gmail.com
}

How to cite this paper: Hossain, Md.M. (2020) Organizational Citizenship Behavior and Organizational Commitment among Clinical Nurses in Bangladesh. Open Journal of Nursing, 10, 693-704.

https://doi.org/10.4236/ojn.2020.107049

Received: June 10, 2020

Accepted: July 12, 2020

Published: July 15, 2020

Copyright $\odot 2020$ by author(s) and Scientific Research Publishing Inc. This work is licensed under the Creative Commons Attribution International License (CC BY 4.0).

http://creativecommons.org/licenses/by/4.0/

\section{(c) (i) Open Access}

\begin{abstract}
Organizational citizenship behavior becomes one of the significant factors that enhance the organizational efficiency. Organizational citizenship behavior has been defined as behaviors that an employee voluntarily engages in organization that promote the effectiveness of clearly rewarded by the organization. However organizational commitment is very beneficial for the organization because it reduces the absenteeism rate and turnover ratio and enhances the organization productivity. In all of the organization, organizational commitment exerts a positive effect on the nurses' performance. The aim was to assess the relationship between organizational citizenship behavior and organizational commitment among nurses. The descriptive correlational design was used to explore the relationship between organizational citizenship behavior and organizational commitment among nurses. Simple random sampling was used and sample size was 164 . Data were collected by a self-structured questionnaire during November 2019 to December 2019 at Dhaka Medical College Hospital. Data were analyzed using SPSS version 21. The result showed that average age of the participants was 34.19 years old. There were statistically positive significant relationships between organizational citizenship behavior with organizational commitment $(\mathrm{r}=0.82, \mathrm{p}=$ $0.000)$, organizational citizenship behavior with working ward $(\mathrm{F}=6.31, \mathrm{p}=$ $0.000)$ and organizational commitment with working ward $(\mathrm{F}=4.45, \mathrm{p}=$ 0.002). Based on the results of this study, it is indicated that lack of OCB \& OC among nurses' is moderate level. The findings of this study will suggest reducing organizational hazard, and developing citizenship behavior and organizational commitment that enhance high outcome in health care organizations \& quality of care. So hospital should provide in-service training for nurses' and all departments are equally. Predictive study of factors related to OCB \& OC is recommended for future study.
\end{abstract}




\section{Keywords}

Clinical Nurses, Organizational Citizenship Behavior, Organizational Commitment

\section{Introduction}

Organizational citizenship behavior becomes one of the significant factors that enhance the organizational effectiveness to achieve the organizational goal. Organizational behavior is as a discipline that attempted to clarify human behavior and reasons for various kinds of behaviors in an organization [1]. Organizational citizenship behaviors have been defined as behaviors that an employee voluntarily engages in activities to promote the effectiveness but are not clearly rewarded by the organization [2]. "Podsakoff, MacKenzie and Organ [3] defined organizational citizenship behavior as individual behavior that is discretionary, not directly or clearly recognized by the formal reward system, in order to promote the efficient and effective functioning of the organization".

Organizational citizenship behavior increases the preference towards helping and sharing information, and promoting the feeling of responsibility, motivation, and satisfaction within the organization. For these grounds, work quality and patient satisfaction can increase organizational citizenship behavior by precise communication and cooperation for establishing strong relationship with health staff, managers, and workers. Nurses who are the most active members, they should display efficient health services activities to provide high levels of organizational citizenship behavior related goals [4].

Organizational citizenship behavior is to protect the organization against disparaging and an undesirable behavior, which protects the organization's healthy operations, improves incumbents' skills and abilities and increases performance and productivity of organization by efficient co-ordination. More productivity and profitability is the result of organizational citizenship behavior in healthier organizational outcomes. Organizational citizenship behavior helps to make best use of organizational performance of hospital. The two major components of organizational citizenship behavior are compliance, which indicates employees' intention to follow the organizational rules, and altruism, which means employees' voluntary behaviors to assist others and to work [5].

Organizational commitment is the employees' state of being committed to assist in the accomplishment of the organization's goals, and involves the employees' levels of identification, involvement, and loyalty [6]. "Meyer and Allen [7] have identified three types of organizational commitment: affective, continuance, and normative". Organizational commitment plays a crucial role in determining whether an employee will stay with the organization for a longer period of time and work passionately towards achieving the organization's goal. This definition, reflecting an individual's affective commitment, represents a sig- 
nificant approach to the study of organizational commitment and seems to be the most desired form of commitment [8].

The issue of organizational commitment is very important for managers in organization to achieve the goal by effective activities. However organizational commitment toward behaviors is very beneficial for the organization because it reduces the absenteeism rate and turnover ratio and enhances the organizational productivity [9]. In order to increase the competitive advantage, the managers continuously seeking ways to enhance the employee's commitment. Organizational commitment, as an attitude, has been defined as the relative strength of an individual's identification with, and involvement in a specific organization [10].

Commitment phenomena are wide investigated for the reason that they influence individual approach and behaviors at the workplace. Occupational commitment has established to be distinguishable from alternative commitment measures like job involvement and organizational commitment, with minimal dismissal. Regarding organizational commitment, the three-dimensional definition acknowledges affective, continuance, and normative commitment as distinct concepts. The most widely investigated dimension of organizational commitment is affective commitment. Affective commitment defined as the degree to which an individual is emotionally involved to an employing organization through feelings such as loyalty, affection, belongingness, etc. Explanation of the employees' emotional bond or attachment is to an organization [11].

"Van-Scotter [12] had founded significant relationship between organizational citizenship behavior and affective commitment". Literature from "Steyrer, Schiffinger and Hang [13] reveals that organizational commitment not only makes an employee to stay in the organization but also make it possible for the employees to take part in organizational activities". However, in recent decades, organizational citizenship behaviors have emphasized greatly on organizational commitment aspect of employees and it is found to be the significantly correlated [14]. A different study illustrated that between organizational citizenship behavior and organizational commitment there was significant and positive correlation $(\mathrm{r}=0.32$, $\mathrm{p}$-value $<0.05)[15]$.

"Moinul and Tahlil [16] conducted a study to know the effect of recognition practice over affective commitment and organizational citizenship behavior. Their study founded that recognition practice affects affective commitment and affective commitment affects 'organizational citizenship behavior' positively". "Ferdus and Kabir [17] study also showed that organizational citizenship behavior level of bankers in Bangladesh is high". "Nesa, Kunaviktikul and Wichaikhum [18] study shown that the level of overall organizational citizenship behavior was at a moderate level ( $\bar{X}=54.92, \mathrm{SD}=1.57)$ in Bangladesh".

\section{Purpose of the Study}

The aim of the study was to explore the relationship between organizational citizenship behavior and organizational commitment among nurses at a medical college hospital in Bangladesh. 


\section{Methods}

The descriptive correlational study design was conducted at Dhaka Medical College Hospital. The total numbers of 164 (estimated by using "G" power analysis) samples were recruited by simple random sampling technique. The instrument consisted of two parts including: The Demographic Data Questionnaire and organizational citizenship behavior \& organizational commitment Questionnaire which was measured by 4-point Likert scale. Data was collected by structure self administered questionnaire. Two sample t-test, ANOVA and correlation were used for data analysis.

\section{Ethical Consideration}

Before the study, written ethical consent was obtained from the ethical boards and hospital. Moreover, all of the participants gave written consent prior to participating in the study.

\section{Result}

Analysis was performed on the data from 164 nurses'; the subjects age ranged from 24 to 57 years with mean of 34.19 years and ( $S D=8.02)$. Majority 143 (87.2\%) subjects were female and very few $21(12.8 \%)$ subject were male. Number of extreme subjects had Muslim 137 (83.5\%), were Hindus 23 (14.0\%) and Christian was 4 (2.4\%). Most of the subjects were married 138 (84.1\%) and only 26 (15.9\%) were single. Number of subjects had diploma in nursing 94 (57.3\%) where as $51(31.1 \%)$ were Bachelor in nursing while 19 (11.6\%) had done Masters in nursing/MPH.

The subjects service experience ranged from 2 to 37 years with a mean of 10.97 years and $(\mathrm{SD}=8.45) .40(24.4 \%)$ number of the subjects were working at surgery department and the rest of the subjects were working at others ward/department. About three forth of the subjects hadn't get any training 119 (72.6\%) in the year 2018-2019. Response rate of the participants is $85.86 \%$ and the Cronbach's alpha coefficient of the questionnaires was 0.97 . The level of organizational OCB but OC is moderate.

Table 1 showed that there was a statistically significant relationship between organizational citizenship behavior with ward $(F=6.31, p=0.000)$, whereas (3.28) $\mathrm{CCU}$ ward was a high level of $(\mathrm{M}=3.28, \mathrm{SD}=0.35)$ behavior compare with others ward. Therefore, nurses had no significant relationship between organizational citizenship behavior with age, gender, religion, marital status, nursing education, service experience and training.

Table 2 showed that there was a statistically strong significant relationship between organizational commitment with working ward $(F=4.45, p=0.002)$, whereas nurses' who were working at CCU ward they had high level of organizational commitment $(\mathrm{M}=3.31, \mathrm{SD}=0.46)$ compare with others ward. Therefore, nurses had no significant relationship between organizational commitment with age, gender, religion, marital status, nursing education, service experience and training. 
Table 3 showed that there was a statistically strong significant relationship between organizational citizenship behavior and organizational commitment $(\mathrm{r}$ $=0.82, \mathrm{p}=0.000)$.

Table 1. Relationship between demographic characteristic and organizational citizenship behavior.

\begin{tabular}{|c|c|c|c|c|}
\hline Variable & Category & Mean \pm SD & $\mathrm{t} / \mathrm{r} / \mathrm{F}$ & (p) \\
\hline Age & & & -0.06 & 0.420 \\
\hline \multirow{2}{*}{ Gender } & Male & $2.91 \pm 0.37$ & \multirow{2}{*}{-1.35} & \multirow{2}{*}{0.178} \\
\hline & Female & $3.05 \pm 0.46$ & & \\
\hline \multirow{2}{*}{ Religion } & Muslim & $3.03 \pm 0.04$ & \multirow{2}{*}{0.05} & \multirow{2}{*}{0.959} \\
\hline & Non-Muslim & $3.03 \pm 0.07$ & & \\
\hline \multirow{2}{*}{ Marital Status } & Single & $3.12 \pm 0.08$ & \multirow{2}{*}{1.04} & \multirow{2}{*}{0.299} \\
\hline & Married & $3.02 \pm 0.03$ & & \\
\hline \multirow{3}{*}{ Education } & Diploma in Nursing & $3.02 \pm 0.49$ & & \\
\hline & Bachelor in Nursing & $3.08 \pm 0.40$ & \multirow[t]{2}{*}{0.42} & \multirow[t]{2}{*}{0.656} \\
\hline & Masters in Nursing/MPH & $3.04 \pm 0.40$ & & \\
\hline \multirow[t]{3}{*}{ Service Experience } & & & \multirow[t]{3}{*}{0.04} & \multirow[t]{3}{*}{0.537} \\
\hline & Surgery & $3.09 \pm 0.37$ & & \\
\hline & Medicine & $2.91 \pm 0.36$ & & \\
\hline \multirow[t]{3}{*}{ Ward } & $\mathrm{CCU}$ & $3.28 \pm 0.35$ & \multirow[t]{3}{*}{6.31} & \multirow[t]{3}{*}{0.000} \\
\hline & Dialysis & $3.10 \pm 0.44$ & & \\
\hline & Operation Theater & $2.78 \pm 0.57$ & & \\
\hline \multirow{2}{*}{ Training in $2018-19$} & Yes & $3.08 \pm 0.41$ & \multirow{2}{*}{0.73} & \multirow{2}{*}{0.465} \\
\hline & No & $3.02 \pm 0.47$ & & \\
\hline
\end{tabular}

Table 2. Relationship between demographic characteristic and organizational commitment.

\begin{tabular}{|c|c|c|c|c|}
\hline Variable & Category & Mean \pm SD & $\mathrm{t} / \mathrm{r} / \mathrm{F}$ & (p) \\
\hline Age & & & 0.04 & 0.584 \\
\hline \multirow{2}{*}{ Gender } & Male & $2.93 \pm 0.47$ & \multirow{2}{*}{-1.62} & \multirow{2}{*}{0.106} \\
\hline & Female & $3.13 \pm 0.52$ & & \\
\hline \multirow{2}{*}{ Religion } & Muslim & $3.10 \pm 0.53$ & \multirow{2}{*}{0.11} & \multirow{2}{*}{0.912} \\
\hline & Non-Muslim & $3.09 \pm 0.47$ & & \\
\hline \multirow{3}{*}{ Marital Status } & Single & $3.22 \pm 0.47$ & \multirow{2}{*}{1.26} & \multirow{2}{*}{0.208} \\
\hline & Married & $3.08 \pm 0.53$ & & \\
\hline & Diploma in Nursing & $3.06 \pm 0.56$ & & \\
\hline \multirow[t]{2}{*}{ Education } & Bachelor in Nursing & $3.17 \pm 0.46$ & \multirow[t]{2}{*}{0.76} & \multirow[t]{2}{*}{0.465} \\
\hline & Masters in Nursing/MPH & $3.13 \pm 0.48$ & & \\
\hline \multirow[t]{3}{*}{ Service Experience } & & & \multirow[t]{3}{*}{0.08} & \multirow[t]{3}{*}{0.266} \\
\hline & Surgery & $3.20 \pm 0.54$ & & \\
\hline & Medicine & $2.95 \pm 0.33$ & & \\
\hline \multirow[t]{3}{*}{ Ward } & $\mathrm{CCU}$ & $3.31 \pm 0.46$ & \multirow[t]{3}{*}{4.45} & \multirow[t]{3}{*}{0.002} \\
\hline & Dialysis & $3.19 \pm 0.46$ & & \\
\hline & Operation Theater & $2.85 \pm 0.63$ & & \\
\hline \multirow{2}{*}{ Training in 2018-19 } & Yes & $3.12 \pm 0.51$ & \multirow{2}{*}{0.20} & \multirow{2}{*}{0.840} \\
\hline & No & $3.10 \pm 0.53$ & & \\
\hline
\end{tabular}


Table 3. Relationship between organizational citizenship behavior and organizational commitment.

\begin{tabular}{cccc}
\hline \multicolumn{2}{c}{ Correlations } & \\
\hline & & OCB & OC \\
\hline \multirow{2}{*}{ OCB } & Pearson Correlation & 1 & $0.828^{* *}$ \\
& Sig. (2-tailed) & & 0.000 \\
& $\mathrm{~N}$ & 164 & 164 \\
OC & Pearson Correlation & $0.828^{* *}$ & 1 \\
& Sig. (2-tailed) & 0.000 & 164 \\
\hline
\end{tabular}

${ }^{* *}$ Correlation is significant at the 0.01 level (2-tailed).

\section{Discussion}

The proposition that younger and older employee may view work and self in fundamentally different ways is not new. "Wagner and Rush [19] pointed out that 35 - 55 year are strong sense of self and work". In this study mean age of the respondent are 34.19 years and $\mathrm{SD}=8.02$, whereas "Jahangir, Akber and Haq [20] mention that younger employees coordinate their needs with organizational needs more flexibly". The majority of the subjects were female nurses' (87.2\%). In Bangladesh, more female (93\%) nurses' are currently working in the hospitals, and this is similar to many other countries all over the world [21]. "Karimi and Alavi [22] reported that Florence Nightingale established modern nursing from that period of time most of the female people were entering this profession from her adverting are motivating likely to come enter in nursing". About maximum of the subjects was Muslim (83.5\%). In Bangladesh, there are four religions that recognized by government: Muslim, Hindu, Christian and Buddhist. Islam was the largest religion in Bangladesh (90\%) and the rest of others religion [23]. The legal marriage age for a girl was 18 years and for a boy was 21 years in Bangladesh [24]. In my study most of the responded (84.1\%) were married.

The education level of the respondents was (57.3\%) diploma in nursing. "Bangladesh Nursing \& Midwifery Council [25] updated statement that total diploma nurses were 83.62\%". This level of education would make them need more knowledge on organizational citizenship behavior. The study illustrated that there were no significant relationship between organizational citizenship behavior in each education level Diploma in nursing, B.Sc in nursing and M.Sc in nursing $(\mathrm{M}=60.22,61.69,60.84)$. Sadodin et al., [26] proved that graduate were more $(M=95.17, S D=9.70)$ OCB than under graduate $(M=91.00, S D=11.64)$. The study findings showed that the total mean score of nurses' service experience was at a low level $(\mathrm{M}=10.97, \mathrm{SD}=8.45)$. Last five year huge number of 19638 nurses recruited in Bangladesh they were need to developed their knowledge, attitude and commitments [27].

In Bangladeshi nurse ward placement system are not so good, nursing author- 
ity wasn't maintain the specialty nurses place in special ward, whereas $99 \%$ nurses provided bed side care [28]. This study results showed that (24.4\%) number of nurses were working in surgery ward. The educational programs that have been developed within this collaboration the enhanced specialized nurse training program the Bangladeshi nurses have received continuing professional improvement based on Western standards of nursing [29]. The study results showed that majority of nurses wasn't got training in 2018-2019 year (72.6\%). Ortega et al., [30] demonstrate that $53.8 \%$ of nurses don't consider the training received to be relevant to the needs of the workplace. However training and education were directly linked to nurses' career satisfaction. Healthy work environments were identified by nurses as those that invested in continuing professional development opportunities to ensure continuous growth in their practice and provide optimal quality patient care [31].

The study findings showed that average mean score of organizational citizenship behavior was $3.03( \pm 0.45)$ and organizational commitment were $3.10( \pm 0.52)$. The findings of this study indicated that the nurses' had moderate level of OCB \& OC. "Altuntaş [4] founded that Nurses were originate to display high levels of organizational citizenship behavior".

In addition, I showed that there was female nurses OCB \& OC both are 3.05 $( \pm 0.46), 3.13( \pm 0.52)$ more than male $2.91( \pm 0.37), 2.93( \pm 0.47)$ other than there are no significant relation. Moreover, "Dargahi, Alirezaie and Shaham [33] founded that there was significant correlation between genders with nurses". However, a previous study also founded that male nurses are always facing different kind of problems in both government and private hospital settings. In Bangladesh male nurses are, disregard and discrimination compared with female nurses therefore, given less or denied attitude facilitated male nurses for mounting their career in highest level as well [33]. On the other hand "Terzi [34] be evidence for male teacher OCB \& OC both are $4.76( \pm 0.85), 3.08( \pm 0.51)$ more than female 4.97 $( \pm 0.86), 2.92( \pm 0.51)$ ".

Using by ANOVA methods I found that there was a positive significant relationship $(\mathrm{F}=6.31, \mathrm{p}=000),(\mathrm{F}=4.45, \mathrm{p}=002)$ between working ward and OCB \& OC. However, CCU ward nurses' was more OCB \& OC $3.28( \pm 0.35), 3.31$ $( \pm 0.46)$ than others ward. DMCH authorities should be observed this department very carefully. Thus, Alammar et al., [35] conclude that the characteristics of the work setting for nurses in the general ward or in a specialized unit do not have a significant impact on job involvement. "Israel et al., [36] proved that working ward $(\mathrm{F}=7.72, \mathrm{p}=0.000)$ were significant predictors of organizational commitment among nurses and surgery ward was more $73.41( \pm 7.50)$ than others ward".

Moreover I demonstrate that highly experience (20 - 37 years) nurses OCB \& OC both were $3.05( \pm 0.46), 3.19( \pm 0.52)$ more than tiny experience ( 2 - 19 years) nurses $3.03( \pm 0.45), 3.09( \pm 0.52)$. On the other hand "Terzi [34] mentioned that experienced teacher OCB was more and low experience teacher OC was more than experienced". 
"Noor [9] showed that the correlation value between training and development opportunities and organizational commitment is $\mathrm{r}=0.351, \mathrm{p}=0.01$ and the beta value is 0.124 which shows the significant relationship between the training \& development opportunities and organizational commitment". In the study illustrated that education and training significantly $(r=0.36, p=000) \mathrm{im}-$ prove organizational commitment. I founded that significant correlation between work place satisfaction \& OCB $(r=0.37, p=000)$, whereas "Bishwajit, Khumyu and Boonyanurak [37] proved that a significant correlation between organizational commitment and job satisfaction $(\mathrm{r}=0.32, \mathrm{p}<0.01)$ ". In this study demonstrate that positive significant correlation between leader command \& OC $(\mathrm{r}=0.57, \mathrm{p}=000)$. On the other hand "Khan and Rashid [14] bear out significant correlation between leadership \& OC $(r=0.52, p=010)$ ". Another study founded that significant correlation between team oriented \& OC $(r=$ $0.44, \mathrm{p}=000)$. In this study as well I founded that significant correlation between teamwork \& OC $(r=0.44, p=000)$ [13].

The results divulge that the organizational commitment and organizational citizenship behavior are very closely associated with each other. The correlation value between OCB and OC is $(r=0.82, p=0.000)$. According to "Noor [9] found that there was a significant $(r=0.80, p=0.01)$ relationship between organization citizenship behavior and organizational commitment. Another Bangladeshi study show that there was a significant $(r=0.23, p=0.00)$ relationship between organization citizenship behavior and organizational commitment [17]". On the other hand "Khan and Rashid [14] showed that the correlation between organization commitment and organization citizenship behavior was positive and significant $(\mathrm{r}=0.417, \mathrm{p}<0.01)$ ". "Jafari, Sadeghi, and Zarnagh [15] founded that Between OCB and organizational commitment there was significant and positive correlation $(\mathrm{r}=0.32$, p-value $<0.05)$ ". Although another researchers explained that there was a positive and significant relationship between organizational commitment and organizational citizenship behavior $(\mathrm{r}=$ $0.181, \mathrm{p}=0.040)[38]$.

\section{Conclusions}

The current study indicated that there was a positive significant relationship between organizational citizenship behavior and organizational commitment. According to the findings, it is concluded that notice to OCB concept and its establishment in organizations can be useful in predicting some organizational concepts like organizational commitment and performance. Therefore, the nurses' organizational citizenship behavior and organizational commitment should be enhanced by making use of appropriate and effective strategies. Nurses are the first people who deal with and are responsible for their patients. These findings suggested an increase level of nurses' OCB \& OC by increasing training, loyalty, opportunity, teamwork, safety work environment \& job satisfaction etc. But engaging in OCB is just a half of the way to the good organizational effectiveness 
because task performance must be on high level and OCB is there only to contribute to the organizational effectiveness.

\section{Limitation of the study:}

Several limitations were inherent in the methodology used in this study. Firstly, the sample was recruited from 5 departments and only one hospital in Bangladesh. Secondly, this study used a set of self administer questionnaire for data collection that may not reflect the actual data. Thirdly, due to limited study in Bangladesh it was difficult to comparison. Therefore, generalizations that can be made from the study are limited.

\section{Recommendation:}

Based on the results of this study, it is indicated that lack of OCB \& OC among nurses' is moderate level. To improve the quality of nursing care, OCB \& OC, the following implications and recommendations are offered.

\section{Nursing training and education:}

The results of the study indicated that nurse's inadequate in-service training program may be the cause. Thus, it is recommended that the syllabus in Bangladesh Nursing Curriculum should be reviewed and added comprehensive program regarding OCB \& OC, so that nursing students would be well-prepared before graduation. Up-to-date in-service training program will be able to provide new knowledge which help nurses' to enhance OCB \& OC.

\section{Nursing research:}

The findings from this study will provide a reference criterion for further studies in the field of OCB \& OC in Bangladesh. This study can be improved by increasing the sample size and setting to enhance the generalizability. At least two setting would be better for comparing nurses' OCB \& OC. A replication of this study using observation method is recommended to examine the level of nurses' OCB \& OC. Predictive study of factors related to OCB \& OC is recommended for future study.

\section{Conflicts of Interest}

The author declares no conflicts of interest regarding the publication of this paper.

\section{References}

[1] Velickovska, I. (2017) Organizational Citizenship Behavior-Definition, Determinants and Effects. Engineering Management, 3, 40-51.

[2] Kwantes, T.C., Karam, M.C., Kuo, C.H.B. and Towson, S. (2008) Culture's Influence on the Perception of OCB as In-Role or Extra-Role. International Journal of Intercultural Relations, 32, 229-243. https://doi.org/10.1016/j.ijintrel.2008.01.007

[3] Organ, D.W., Podsakoff, P.M. and Mackenzie, S.B. (2006) Organizational Citizenship Behavior: Its Nature, Antecedents, and Consequences. SAGE Publications, London.

[4] Altuntas, S. and Baykal, U. (2014) Organizational Citizenship Behavior Levels of Nurses and Effective Factors. Journal of Health and Nursing Management, 1, 89-98. 
https://doi.org/10.5222/SHYD.2014.089

[5] Islam, M.H., Akter, F. and Lecturer, F.A. (2015) Factor Affecting Organizational Citizen-Ship Behaviour of Corporate Sector in Bangladesh. European Journal of Business and Management, 7, 2222-2839.

[6] Caught, K., Shadur, M.A. and Rodwell, J.J. (2000) The Measurement Artifact in the Organizational Commitment Questionnaire. Psychological Reports, 87, 777-788.

[7] Meyer, J. and Allen, N. (1997) Commitment in the Workplace: Theory, Research, and Application. Human Resource Development Quarterly, 9, 309-312.

https://onlinelibrary.wiley.com/doi/abs/10.1002/hrdq.3920090309

[8] Ghina, A. (2012) The Influence of Corporate Culture on Organizational Commitment; Case Study of Civil Government Organizations in Indonesia. International Journal of Basic and Applied Science, 1, 156-170.

[9] Noor, A. (2009) Examining Organizational Citizenship Behavior as the Outcome of Organizational Commitment: A Study of Universities Teachers of Pakistan. Proceedings 2 nd CBRC, Lahore, Pakistan, 14 November 2009.

[10] Boon, O. and Arumugam, V. (2006) The Influence of Corporate Culture on Organizational Commitment: Case Study of Semiconductor Organizations in Malaysia. Sunway Academic Journal, 3, 99-115.

[11] Chang, E. (1999) Career Commitment as a Complex Moderator of Organizational Commitment and Turnover Intention. Human Relations, 52, 1257-1258. https://doi.org/10.1177/001872679905201002

[12] Van Scotter, J.R. (2000) Relationships of Task Performance and Contextual Performance with Turnover, Job Satisfaction, and Affective Commitment. Human Resource Management Review, 10, 79-95. https://doi.org/10.1016/S1053-4822(99)00040-6

[13] Steyrer, J., Schiffinger, M. and Lang, R. (2008) Organizational Commitment-A Missing Link between Leadership Behavior and Organizational Performance? Scandinavian Journal of Management, 24, 364-374. https://doi.org/10.1016/j.scaman.2008.04.002

[14] Khan, S.K., Rahman, A., Zabid, M. and Rashid, A. (2015) The Mediating Effect of Organizational Commitment in the Organizational Culture, Leadership and Organizational Justice Relationship with Organizational Citizenship Behavior: A Study of Academicians in Private Higher Learning Institutions in Malaysia. International Journal of Business and Social Science, 3, 83-91.

[15] Jafari, H., Sadeghi, A. and Zarnagh, J. (2010) The Relationship between Organizational Citizenship and Organizational Commitment in Has Heminezhad Hospital. Jundishapur Journal of Health Science, 3, 52-61.

[16] Moinul, M.H. and Tahlil, M.A. (2009) The Effect of Recognition Practice over Affective Commitment and OCB: An Empirical Study in Bangladesh. Independent Business Review, 2, 65-81.

[17] Ferdus, Z. and Kabir, T. (2018) Effect of Job Satisfaction and Organizational Commitment on OCB: Study on Private Banks in Bangladesh. World Journal of Social Sciences, 8, 57-69.

[18] Nesa, M., Kunaviktikul, W. and Wichaikhum, O.A. (2014) Participation in Decision Making and Organizational Citizenship Behavior among Nurses in Medical College Hospitals, Dhaka, The People's Republic of Bangladesh. Nursing Journal, 45, 192-202.

[19] Wagner, S.L. and Rush, M.C. (2000) Altruistic Organizational Citizenship Behavior: Context, Disposition and Age. The Journal of Social Psychology, 140, 379-391. 
https://doi.org/10.1080/00224540009600478

[20] Jahangir, N., Akber, M.M. and Haq, M. (2004) Organizational Citizenship Behavior: Its Nature and Antecedents. BRAC University Journal, 1, 75-85.

[21] Mahmud, S. (2013) Health Workforce in Bangladesh. Bdnews24.Com

[22] Karimi, H. and Alavi, M.N. (2015) Florence Nightingale: The Mother of Nursing. Kashan University of Medical Science. https://doi.org/10.17795/nmsjournal29475

[23] US Department of State. 2017 Report on International Religious Freedom-Bangladesh. https://www.state.gov/j/drl/rls/irf/2017/sca/281018.htm

[24] Jisun, F.T. (2016) Early Marriage of Women: The Case of Bangladesh. World Journal of Social Sciences, 6, 51-61.

[25] Bangladesh Nursing \& Midwifery Council. http://bnmc.portal.gov.bd/sites/default/files/files/bnmc.portal.gov.bd/page/4ccb8b5f _4b8a_486a_8f1d_66e23a7dcb8b/Datasheet\%20April\%2019.jpg

[26] Sadodin, S.N., Daghian, Z.K., Esmaily, H. and Hooshmand, E. (2016) The Relationship between Organizational Citizenship Behavior, Job Satisfaction, and Occupational Stress among Midwives Working in Healthcare Centers of Mash Had, Iran, 2014. Journal of Midwifery and Reproductive Health, 4, 622-630.

[27] Bangladesh Public Service Commission. http://www.bpsc.gov.bd/site/view/psc_exam/Non-Cadre\%20Examination

[28] Rozario, M.D., Adhikary, H., Gazi H.R. and Begum, D. (2018)Nurses' Roles in Patient Care in Tertiary Level Hospitals in Bangladesh. Bangladesh Medical Research Council Bulletin, 44, 138-144. https://doi.org/10.3329/bmrcb.v44i3.39937

[29] Barron, A.-M., Moran, J., Nina, S.S., Harlow, J., Gyawali, M., Hossain, F., Brezina, M., Callahan, C., Curran, J., Danielson, C., Fitzgerald, E., Foster, J., Erhardt, E., Shaughnessy, C., Yeh, C.A. and Dey, R.B. (2017) Building Specialized Nursing Practice Capacity in Bangladesh: An Educational Program to Prepare Nurses to Care for Oncology and Bone Marrow Transplant Patients in Dhaka, Bangladesh. Journal of Global Oncology, 4, 1-6. https://ascopubs.org/journal/jgo

[30] Ortega, B.C.M., Cecagno, D., Llor, A.M.S., Siqueira, H.C.H., Montesinos, M.J.L. and Soler, M.L. (2015) Academic Training of Nursing Professionals and Its Relevance to the Workplace. Revista Latino-Americana de Enfermagem, 23, 404-410.

https://www.ncbi.nlm.nih.gov/pmc/articles/PMC4547062/pdf/0104-1169-rlae-23-03 00404.pdf

[31] Price, S. and Reichert, C. (2017) The Importance of Continuing Professional Development to Career Satisfaction and Patient Care: Meeting the Needs of Novice to Mid- to Late-Career Nurses throughout Their Career Span. Administrative Sciences, 7, 17. http://www.mdpi.com/journal/admsci https://doi.org/10.3390/admsci7020017

[32] Dargahi, H., Alirezaie, S. and Shaham, G. (2012) Organizational Citizenship Behavior among Iranian Nurses. Iranian Journal of Public Health, 41, 85-90.

[33] Abdelkader, M.A. and Abdelrahman, S. (2016) Attitudes of Both Male and Female Nurses toward Men in Nursing in Minia University Hospital. IOSR Journal of Research \& Method in Education, 6, 46-55.

[34] Terzi, R.A. (2015) Organizational Commitment and Citizenship Behaviors among Teachers. Anthropologist, 21, 350-360. https://doi.org/10.1080/09720073.2015.11891824

[35] Alammar, K., Alammar, M., Alqahtani, S. and Ahmad, M. (2016) Organizational Commitment and Nurses Characteristics as Predictors of Job Involvement. Cana- 
dian Journal of Nursing Leadership, 29, 59-69.

https://doi.org/10.12927/cjnl.2016.24983

[36] Israel, B., Kifle, W., Tigist, D. and Fantahun, W. (2017) Organizational Commitment and Its Predictors among Nurses Working in Jimma University Specialized Teaching Hospital, Southwest Ethiopia. Primary Health Care, 7, 1-8.

[37] Bishwajit, M., Khumyu, A. and Boonyanurak, P. (2016) Relationships between Organizational Commitments, Supervisory Support and Job Satisfaction of Nurses in a Public Specialized Hospital, Bangladesh. Bangladesh Journal of Medical Science, 15, 39-43. https://doi.org/10.3329/bjms.v15i1.27137

[38] Khaleh, L.A.B.C. and Naji, S. (2016) The Relationship between Organizational Commitment Components and Organizational Citizenship Behavior in Nursing Staff. International Journal of Medical Research \& Health Sciences, 5, 173-179. 